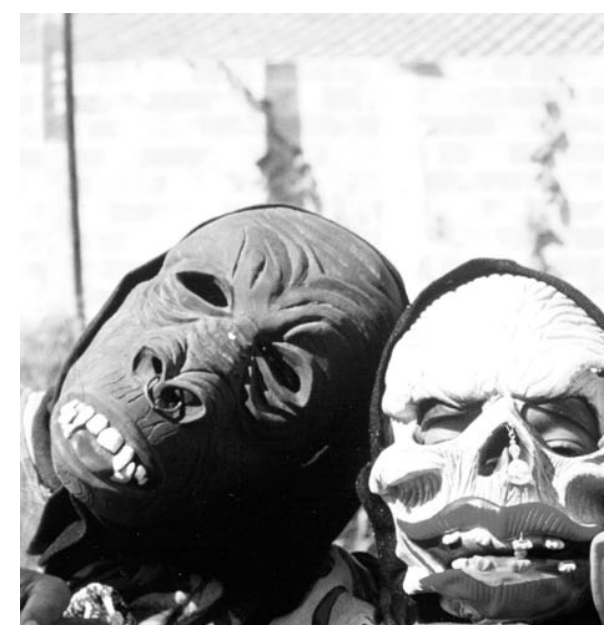

artigos

\title{
A traição nas relações de trabalho da Universidade
}

Aparecida Mari Iguti 1

IGUTI, A. M. Betrayal in the university's workplace, Interface - Comunic, Saúde, Educ, v.6, n.11, p.89-104, 2002.

This is a short essay in which we point out issues for reflection regarding the University and betrayal in work relations, which, we believe, has become more intense in the last few years. Based on the testimonies of academic staff and researchers and on the available literature, we have tried to contextualize the world of university work and its current dynamics, which foster this type of attitude. Certain possibilities were raised concerning the reason why they occur, including the issues of power and jealousy. It was considered that betrayal may be regarded as the beginning of the decay of human relations, from an individual point of view, as opposed to solidarity and the collective aspects of work.

KEY-WORDS: Universities; interprofessional relations; work.

Trata-se de pequeno ensaio, no qual levantamos pontos para reflexão sobre a Universidade e a traição nas relações de trabalho que, parece-nos, têm se intensificado nos últimos anos. Baseados em depoimentos de acadêmicos e pesquisadores e em literatura disponível, procurou-se contextualizar o mundo do trabalho na universidade, com suas atuais dinâmicas que propiciam este tipo de atitude. Levantaram-se algumas possibilidades do porquê de sua ocorrência, entre elas as questões do poder e da inveja. Considerou-se que a traição pode ser um indício da degradação das relações humanas, numa perspectiva individualista, contra a solidariedade e o coletivo do trabalho.

PALAVRAS-CHAVE: Universidade; relações interprofissionais; trabalho.

${ }^{1}$ Docente do Departamento de Medicina Preventiva e Social da Faculdade de Ciências Médicas da Universidade Estadual de Campinas (FCM/UNICAMP. <iguti@unicamp.br> 


\section{Introdução}

Este texto pretende ser uma provocação: se para você esta questão não tiver nenhum sentido particular, convido-o a uma leitura, por simples curiosidade. A intenção foi de fazer uma reflexão livre, sem maiores preocupações; surgiu a partir de experiências e de vivências de colegas, alunos e pacientes, relatadas em situações bastante diversas. As informações foram coletadas ao longo do tempo. Percebemos que havia certa semelhança entre os relatos de distintos "casos", no 'jeito' de acontecer. Inicialmente este texto foi pensado só para "uso interno", mas quando algumas pessoas leram, verificamos, com certa surpresa, que não era tratado como algo anedótico, levava a novos depoimentos e a reflexões. Trata-se, portanto, do resultado dessas múltiplas combinações e que lançamos, a seguir, como uma síntese inicial aberta a novas análises.

\section{A questão}

Trabalhando nos últimos anos em uma instituição pública, com o olhar da formação em Saúde Ocupacional, observamos fatos que, sem dúvida, sempre existiram, que vêm ocorrendo, porém, com intensidade e freqüência maiores. Que fatos são estes? São ocorrências que acabam por afastar ou bloquear as atividades de profissionais da instituição.

Citamos alguns fatos, tais como o afastamento de docentes; a tentativa de demissão de docentes e funcionários; transferências de docentes e funcionários de setores e atividades; a não contratação em regime estável de docentes; a colocação de funcionários "à disposição"; a perseguição às pessoas que compõem o grupo do "atingido"; o bloqueio, a obstrução, o não acolhimento de atividades, mesmo que (aparentemente) de interesse para a instituição; a avaliação negativa de relatórios e projetos que podem afetar a vida funcional (no limite do desrespeito); a recusa de projetos e outras formas que dificultam a vida laboral de pessoas.

A nossa interrogação é: porque ocorrem, e porque esses profissionais são atingidos?

Uma das características da universidade pública é de uma certa estabilidade de emprego, garantida pela constituição atual, desde que o funcionário não incorra em delitos estabelecidos na legislação específica, e que possam caracterizar demissão por justa causa. Outros problemas funcionais, como a falta de compatibilidade com a chefia, podem levar um funcionário a ser "colocado à disposição" da instância imediatamente superior, na universidade. Não vamos neste trabalho considerar as outras formas mais precárias de relações de trabalho, quando estas questões ficam opacas, pois sequer chegam a vir à tona.

Nenhuma das pessoas cujos casos conhecemos e que serviram de base para esta reflexão, encontrava-se na categoria de funcionário sem produtividade, nem com problemas de natureza ética, ou sob algum tipo de processo legal que pudesse ser alegado para afastamento ou demissão por justa causa; pelo contrário, esses funcionários tiveram, todos, ocorrências 'não justificadas', com ausência de quaisquer fatos reais que pudessem ser caracterizados como de delito. Esses processos têm envolvido chefias e alguns outros profissionais que 
possuem algum poder, direto ou indireto. A forma de se conduzir é geralmente indireta ou à revelia do principal interessado, que só fica sabendo uma vez os fatos consumados. Existe, pelo conjunto do grupo, aceitação, omissão, ou atuação efetiva prejudicando o profissional, daí o termo utilizado de "traição".

Neste trabalho, consideramos traição todo e qualquer ato, ativo ou passivo, por interferência ou por omissão, feito por trás, pelas costas, visando com isso prejudicar, causar dano, problemas, de ordem individual e institucional, relacionado ao trabalho.

Algumas características dessas pessoas "traídas" (não iguais ou presentes em todos os casos) incluem ter uma posição de independência, autonomia, uma postura crítica na tomada de decisões, um certo perfil 'competente', combativo, possuir uma certa liderança, ou ainda, procurar fazer corretamente e sobretudo não pertencer, de forma visceral, às 'panelinhas'.

Notamos pressões diversas que produzem a desarticulação de docentes com maior crítica, afastamento das pessoas, com perda de relações coletivas, cada um defende-se por si só:

... algumas coisas começaram a acontecer de forma grave no departamento. A primeira foi a questão persecutória em cima de pessoas que estavam do meu lado...- todas foram praticamente demitidas (...) A grande dúvida continua na cabeça de todo mundo. Quer dizer está havendo influência política para uma inércia, ou não?(...) porque há interesse em não continuar o trabalho, isso me parece bem claro (...) Interessa a muita gente a ineficiência desse nosso serviço. (Massini, 1999, p.28)

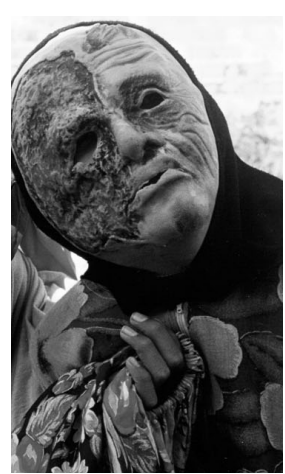

A vida dos funcionários não estáveis é muito diferente dos estáveis e existem pelo menos duas categorias de trabalhadores, sendo que isto também gera reações entre estas. Para funcionários não estáveis, o fim de um contrato de trabalho, seja pelo fim de um projeto de pesquisa e/ou de um serviço, gera pressões $e$ insatisfação; este mesmo fato também gera instabilidades no quadro estável, pois dificulta ou inviabiliza projetos, obriga muitas vezes os docentes/ pesquisadores a procurarem outras fontes de recursos, para continuar a tocar as pesquisas.

O boicote e a obstaculização podem aparecer na forma de ausência de suporte estrutural, técnico: "se não quiser que você escreva uma matéria, desligo o seu computador, ou não dou computador, ou não dou papel para você colocar na impressora. É uma forma velada de punir. Se não quero, não prestigio” (Massini, 1999, p.26).

Desprestigiar figuras com certa capacidade de articulação e independência, prejudicando-as, anulando-as, mesmo que as questões possuam alta relevância institucional; usando argumentos de caráter pessoal, de ser, por exemplo, "chato", "cri-cri", "difícil para se trabalhar", desqualificando-as para as atividades profissionais de maior relevância. Muitas vezes notamos que os interesses individuais se sobrepõem aos coletivos; baixa preocupação com a questão institucional. E diferenças profissionais são tomadas pessoalmente, com grande freqüência. Também o professor passa a ter a função de "captar recursos" para a complementação salarial e para conseguir realizar suas pesquisas, item este, cobrado pela instituição e pelos pares. 
IGUTI, A. M.

\section{Contexto}

A Universidade para o mercado

O essencial é, gradualmente, tornar as universidades fundações

autônomas, de direito privado, que contratem professores e funcionários

pela legislação trabalhista e organizem fundos de pensões para eles. Os

professores poderão alcançar estabilidade depois de alguns anos,

adotando-se o sistema de "tenure" americano. Mas não será estabilidade

automática. Só os melhores alcançarão. As universidades deverão ter

liberdade para contratar, estabelecer salários, planos de carreira. (Bresser

Pereira, 2000, p.11)

Este trecho foi escrito pelo ministro da reforma do Estado do governo federal de Fernando Henrique Cardoso, e professor de Economia da Fundação Getúlio Vargas, FGV/SP. Este tipo de discurso nos coloca claramente o ideário neoliberal e privatizante encadeado pelo governo. Também traz claramente critérios que são altamente seletivos e excludentes, contrariando os princípios da universidade, pois quais poderão ser esses?

"Por que os professores universitários deveriam ter segurança quando tantos outros norte-americanos já não tem?" Segundo Wiener (2000, p.14), a imprensa americana diz que, no mundo acadêmico, a estabilidade no emprego tornou-se obsoleta. A academia deveria submeter-se à lógica de mercado, os administradores das universidades precisam de flexibilidade, que seria preciso buscar o melhor custo/benefício para o emprego de recursos educacionais, como por exemplo substituir professores veteranos por pessoal novo, com salários mais baixos... Para Chait (1999 apud Wiener), a alternativa à estabilidade seria um contrato por prazo limitado, sob o qual professores seriam empregados por três-cinco anos, sem promessa de renovação, ou ainda o trabalho sem prazo definido, de senior ou educador clínico, sob indicações anuais, enquanto o administrador estiver gostando do educador ou não arranjar alguém melhor...Outra forma encontrada pelas universidades americanas é da contratação de professores em tempo parcial, uma vez que não gozam de benefícios concedidos aos estáveis em tempo integral, ainda considerando que somente um quarto dos professores das universidades americanas seja estável.

Quando você tem um pró-reitor de graduação que propõe uma flexibilização da grade curricular para o mercado, você já tem então embutida toda uma decisão que vem da cúpula (...) o que aconteceu nestes últimos seis anos no Brasil foi um desmonte programado, intencional, racional, de todo um sistema de produção de saberes (...) de estruturas de construção de saberes locais, como laboratórios, centros, serviços de apoio. (Romano, 1999, p.22)

Nas universidades, o que prevalece é o modelo da administração eficiente, capaz de gerar seus próprios recursos estabelecendo nexos cada vez mais profundos com o mercado e com a corrida tecnológica. A eficácia de desempenho é medida em termos de sucessos estatísticos, de capitais, produtividade e visibilidade, todos conversíveis em valores de marketing

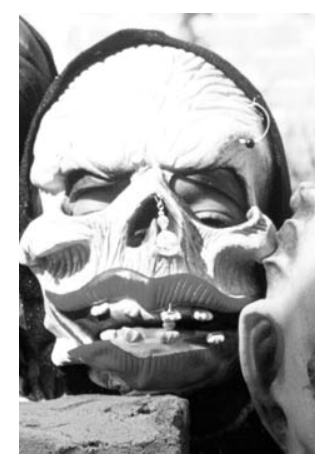




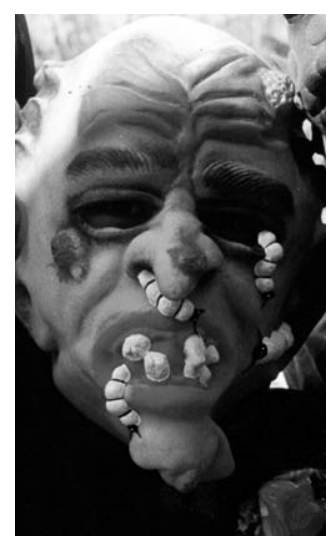

para atrair novas parcerias, dotações e investimentos. Um dos sintomas mais reveladores desse novo quadro é a insistência em que a avaliação dos professores requeira de cada um alguma forma de envolvimento em atividades administrativas. Claro que isso possibilita cortar o número de funcionários ao mínimo. Mas, mais que isso, acumplicia todos nesse novo espírito de racionalidade gerencial. $\mathrm{O}$ professor ideal agora é um híbrido de cientista e corretor de valores. Grande parte de seu tempo deve ser dedicado a preencher relatórios, alimentar estatísticas, levantar verbas e promover visibilidade para si e seu departamento. O campus vai se configurando num imenso pregão. O gerenciamento de meio acabou se tornando fim na universidade. A idéia é que todos se empenhem, no limite de suas forças, para que também compartilhemos do inexorável destino manifesto. (Sevcenko, 2000, p.7)

O recado para os professores das universidades públicas é claro: se quiserem seguir seus postos, saibam que seus salários serão cada vez mais achatados, suas condições de trabalho piores, sem substituição para os que se aposentarem e portanto com cargas de trabalho cada vez maiores. As condições de aposentadoria seguirão sobre pressão e assim se puderem, aposentem-se logo, transfiram-se para universidades privadas para complementar a aposentadoria que evidentemente não lhes basta. Paulo Renato, por um lado, e Pedro Malan, por outro, e FHC, por todos, trabalham assim como quintas colunas do caráter público do Estado, com políticas totalmente funcionais como privatização e a mercantilização da educação, em troca de apoio que recebem da bancada que defende os interesses do ensino privado no Congresso. (Sader, 2000, p.27)

\section{Recursos para trabalhar e viver, núcleos de controle institucional}

Com o salário que recebe nas universidades paulistas, trabalhando em regime de tempo integral, o professor não tem mais condições de exercer a sua função com dignidade e competência: falta-lhe dinheiro para comprar livros e acompanhar a discussão cultural e artística, de inteirarse das transformações tecnológicas que afetam toda produção de conhecimento, falta-lhe pão do espírito. Isso já seria trágico, se não lhe faltasse ainda o principal: a tranquilidade para concentrar a atenção em suas aulas e pesquisas. Atolado na viração, nos bicos para tapar os buracos de cartão de crédito, ele vai se acostumando às práticas do mercado informal de trabalho, adaptando-se à lógica do imediatismo que nos leva a fazer tudo e qualquer coisa em troca de sobrevivência. As marcas da proletarização estão expostas até mesmo na gastura e no envelhecimento precoce de muitos de nós. (Santos, 2000, p.5)

Os postos universitários são extremamente mal pagos, o apoio à pesquisa antes se caracteriza pelo acúmulo de obrigações burocráticas (informes, questionários, ênfase quantitativa em trabalhos que não serão lidos) do que por verbas para conservação e atualização das bibliotecas, para publicação de revistas de periodicidade constante, para o contato com colegas nacionais e estrangeiros. Além disso, como a degradação do ensino vem do curso secundário, as aulas 
passam a ser dadas para turmas sem preparo e interesse, muitas vezes para alunos semi-alfabetizados. Assim o professor, a curto prazo é obrigado a optar por cursos medíocres, a médio prazo se desinteressa progressivamente pelo que faz e a longo prazo internaliza (e esquece) a mediocridade que dele se apropria, isso para não falar dos que já iniciam sua carreira com ela (Lima, 2000).

Na lista de espera dos ansiolíticos e antidepressivos estão "winners" que temem cair para a segunda divisão; “losers" que jamais sairão dos bancos de reserva; cientistas e intelectuais de pires na mão, tentando convencer os "organismos de financiamento" que suas investigações dão lucros; pensadores que param de pensar para se engalfinharem com colegas por uma bolsa de estudos a mais. (Freire Costa, 2000, p.19)

Como afirma Goldenberg, ex-reitor da Universidade de São Paulo (USP) e exministro da Educação (República, 2000, p.28): "Os governos sempre trataram de manter a universidade sob rédeas curtas, colocando-a em uma estrutura administrativa na qual tenham controle, utilizando inclusive instrumentos financeiros". Uma estratégia eficiente, já que ao Estado cabe financiar a universidade pública. Para Dalmo Dalari, jurista e professor da USP (República, 2000, p.28), hoje, as universidades vivem uma falsa autonomia porque não têm como ser autônomas em nenhum aspecto se não têm recursos suficientes para trabalhar".

A crise financeira das universidades impede a contratação de novos profissionais para substituir os que se aposentam e a progressiva adoção pelas reitorias da doutrina neoliberal consagra a idéia de que a atividade intelectual se mede na multiplicação de turmas e disciplinas. Isso transforma os professores em "dadores de aulas" para classes numerosas, aproximando-os de seus colegas das “universidades” privadas. É o que chamo de professorado lúmpen. Contudo, precisamos encarar, por um lado, nossa crescente proletarização em termos econômicos e por outro, nossa insidiosa transformação numa espécie de lumpesinato intelectual. Para começar deveríamos prestar atenção ao modo como hoje somos vistos dentro da sociedade brasileira: como coitados ou otários. (Santos, 2000, p.5)

A universidade está empobrecendo, os salários estão diminuindo. Então ela vai começar (uma discussão) com a perspectiva de - como na classe média - se transformar numa discussão filosófica. A classe média está sendo chamada a uma outra discussão: não pode mais mandar o filho à uma boa escola, não pode mais cuidar da saúde, não pode mais envelhecer, não pode mais ficar doente. ...Com a globalização, a escolha é cada vez mais estreita. Por conseguinte, o campo de pensamento se afunila e a distância em relação à busca da verdade aumenta. E hoje há uma tecnização da pesquisa, quer dizer, há uma necessidade de dinheiro que complica, pois este é distribuído para os centros de pesquisa que aceitam essa instrumentalização. E pensar livremente se dá a partir de um certo estágio, uma certa experiência ou um certo gênio - gênio de

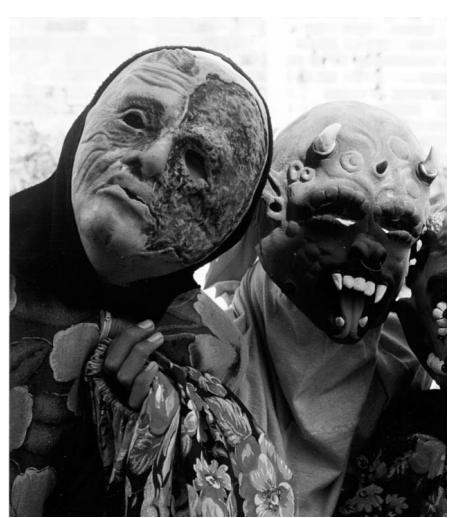


qualquer idade - o que significa um número menor de pessoas, que tem por isso público menor. E o público vai exatamente para o outro lado. A universidade pública seria o lugar do intelectual público. Mas hoje a possibilidade de ser intelectual público é cada vez mais limitada, pelas razões citadas. (Milton Santos, 2000, p.17)

\section{A avaliação como forma de controle} A linguagem formal para o processo é "produtivo e improdutivo", você é classificado em A, B, C, D. Essa classificação determina a distribuição de bolsas, determina auxílios para colóquios, congressos, publicações, enfim, para infraestrutura de pesquisa. Então você tem um controle econômico da produção a partir desses critérios inteiramente abstratos e quantitativos da produtividade...

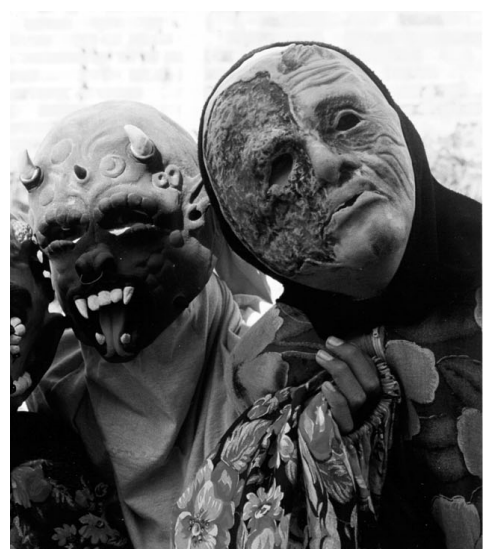

Então consolida-se um processo de fragmentação, de hierarquização da qualidade e de hierarquização dos recursos. $E$ isso, do ponto de vista do contrato de gestão, recebe o nome de autonomia. A autonomia não é o poder da universidade para se autodirigir e decidir currículos, a avaliação etc. A autonomia refere-se à liberdade para encontrar formas convenientes de gestão de recursos quanto à operacionalidade, se ela tem de dar resultados e ser funcional, precisa de um referencial (...) [existe o] Maior número de avaliações, com critérios pouco transparentes, e contraditóriamente, ao mesmo tempo excessivamente quantitativos, rígidos, dificultando a expressão de singularidades. Um dos problemas relaciona-se ao acesso aos recursos humanos $e$ financeiros, então tolher profissionais ao acesso a certos cargos, por exemplo, traz embutido o efeito da impossibilidade a este acesso(...) Então, nos centros de excelência, a produtividade é medida pelo número de publicações, pelo número de orientandos na pós graduação, pelo número de cursos de extensão (...) qual é o sentido dessa brincadeira? É a distribuição de recursos. (Chauí, 1999, p.27)

Não existe um pensamento filosófico ou científico sem direito de errar. E esse direito está sendo negado pelo tipo de avaliação da universidade. Você tem de acertar sempre, é fábrica de pãozinho, a receita foi dada, um mestrado é feito em dois anos e meio, três anos e um doutorado em quatro. E dane-se quem não fez isso aí. E na avaliação também da produção teórica (...) Mas existe gente especializada em avaliação, existem núcleos de avaliação. Pergunto o seguinte: o que eles fazem no campo da pesquisa? Quem é antropólogo e que só avalia os outros (...) De repente, você só tem avaliadores, que avaliam físicos, matemáticos, químicos etc etc... Não conheço indivíduo ou grupo que possa ter um domínio tão grande que possa avaliar tudo isso. O que quer dizer que a avaliação nesse sentido, é picaretagem pura. (Romano, 1999, p.23)

Dejours (1999, p.17) critica essas formas ditas modernas de avaliação, pois, segundo seu olhar, só trazem maior sofrimento no trabalho. 
Sou adversário feroz e definitivo desses métodos de avaliação. O principal objetivo deles é provocar medo nas pessoas. Hoje o principal elemento estruturante do trabalho é o medo, a ameaça do desemprego e da precarização. Essa ameaça se combina com o temor de não conseguir manter o desempenho, o ritmo, os objetivos, de não estar à altura da situação e das mudanças tecnológicas. Nesse quadro, tudo o que você fizer, será avaliado. (...) o que é socialmente útil não é forçosamente produtivo. Como medir por exemplo, a produtividade de um psiquiatra ou de um assistente social? (...) No setor público, por exemplo, o que conta frequentemente é o número de casos tratados. (...) Na realidade, a avaliação do trabalho é uma coisa impossível. O que é decisivo no trabalho é a engenhosidade, os truques de inteligência que driblam os regulamentos para que o sistema funcione, saber resolver problemas imprevistos. Mas tudo isso pertence ao domínio do invisível.

\section{Os motivadores}

Aspectos individuais: será a inveja um forte motivador?

A inveja: A inveja e o ciúme devem ser vistos no contexto histórico e social das instituições, numa sociedade em mutação, competitiva e individualista, cujas circunstancias atuais são agravantes desse quadro (Guerreiro \& Anderson, 1998). Para Shengold (1995) a inveja representa destrutividade primária, pulsão de morte; trata-se de sentimento complexo, em que o objeto da inveja não é o bom objeto, é o objeto onipotente idealizado (Feldman \& De Paola, 1998). Porém, não é tido como patológico pela sociedade.

Para De Gaullejac (1997), a inveja é uma ambição negativa, da vingança, do orgulho ofendido, contra uma comparação humilhante; o autor realizou estudo, por meio de entrevistas com alunos: o indivíduo se compara com o outro, se acha menos e o orgulho fica ferido. Para o sujeito, a inveja implica que os outros tenham boa sorte e o próprio, má sorte (Teigen, 1997). A inveja pode ser compreendida como a resultante parcial de um sentimento subjetivo de injustiça muito grande (Smith et al., 1994).

Segundo Anderson (1987), Jung via na inveja a experiência subjetiva do outro, como defesa das coisas e a grandeza dos outros e não como o ódio herdado do bem. Nesta perspectiva, a inveja emerge como tentativa desesperada de preservar o sentido de ser alguém contra o temor de não ser. Sente-se ameaçado de perder sua identidade, o que lhe causa insegurança, limitação e fragilidade. Do ponto de vista de sua expressão, ela pode ser depressiva, ativa ou neutra. A inveja pode ainda, segundo Sandell (1993), ser entendida como um fenômeno psicoparanóide com desesperança e fantasias persecutórias e sentimento de cisão objetal; existe uma relação estreita entre inveja, narcisismo e admiração. Inveja e admiração são analisadas como vias alternativas, essencialmente contrárias para lidar com situação de privação, quando a pessoa percebe que possui menos que os outros.

A ambição e o medo podem levar a táticas de poder no trabalho; podem ter funções construtivas ou manifestações pouco saudáveis do poder, como o silêncio, com freqüência devastador, críticas públicas, sarcasmo. Embora a inveja seja negada por muitos (os outros são os invejosos), existem recomendações claras $e$ 
publicadas "para evitar as relações doentias de inveja no trabalho", como trabalhar em equipe; adesão a normas e regulamentos não oficiais do trabalho; limitar a autopromoção; evitar a ostentação de riquezas; utilizar a meditação; sair do sistema doente (Horner, 1989).

Lewis (1993) diz, a propósito da inveja, que para compreender como as pessoas funcionam em seu cotidiano, exige-se uma exploração interdisciplinar do fenômeno de mentir e de decepção.

Roussillon (1991) descreve a constituição complexa da psique, em função de experiências vividas que, no processo de elaboração mental, sempre deixa "resíduos", que provocam limitações, num processo dialético; cita Freud, que em 1920, os evocaria por meio da metáfora dos protozoários, em que estes resíduos poderiam operar um retorno destruidor no interior da sua elaboração mental, desenvolvendo uma verdadeira cultura de pulsão de morte, e que Melanie Klein procurou teorizar na noção de ataque invejoso primário. $\mathrm{O}$ espaço de tratamento dos resíduos pode ser uma reunião ou ainda pode se encarnar numa determinada pessoa; esse mecanismo está presente no fenômeno do "bode expiatório" ou da "vítima sacrificial", descrito por Girard (1972 apud Roussillon, 1991, p.139). Freud descreveu, em 1921, a natureza identificadora da coesão grupal, o cimento fantasmático das instituições, atribuindo inversamente à inveja um papel desorganizador.

Uma das hipóteses é que de alguma forma essas pessoas despertam nos integrantes dos grupos de trabalho sentimentos de ameaça, levando as pessoas a sentirem como se tivessem que defender a própria sobrevivência (egóica). Alguns fatos poderiam constituir fontes de ameaça, como por exemplo "o reconhecimento de alguém que vive e trabalha pela sociedade", a ética, a propósito de tentativas de suborno: "..porque a clareza do meu ponto de vista é muito conhecida... não trabalho, não recebo. E todo mundo sabe o que eu tenho, o que não tenho, o que consegui, como pago minhas contas" (Massini (1999, p.26).

Agora, que responsabilidade pública tem alguém que julga um projeto de pesquisa no anonimato mais absoluto? Este anonimato serve para você não prestar contas dos 'dinheiros', mas serve também para você cortar idéias, perseguir inimigos, dar um rumo definido do saber. (Romano, 1999, p.25)

(...) a inveja é dissimulada, camuflada, camufladíssima, uma loucura. As mulheres são mais diretas, mais limpas. Os homens são invejosíssimos.

(Ventura, 1998, p.138)

\section{Narciso}

O conceito do contrato narcísico comporta três idéias: a primeira é que o indivíduo constitui-se em sua própria finalidade e, ao mesmo tempo, membro da cadeia à qual se encontra preso; a segunda é que os pais constituem a criança como portadora dos seus sonhos de desejo não realizados e que o narcisismo primário dela apóia-se no dos pais; e a terceira, que o Ideal do Ego é uma formação comum à psique singular e aos conjuntos sociais, incluindo as instituições. 
Motivações "íntimas” podem ser percebidas: vaidade - "Lógico que o interesse político chama o interesse público, o interesse público chama o interesse financeiro e as coisas vão se complicando por aí..é o domínio da vaidade pessoal"; inveja - "Dizem que a gente nunca deve brilhar muito no lugar onde está, porque corre o risco de alguém olhar e dizer: Puxa, aquele negócio tá brilhando, então eu vou tomar dele"; raiva - "a raiva por diferenças profissionais, entre outros" (Massini, 1999, p.27). O depoimento ilustra bem o individualismo, a competição dentro das organizações, o poder, a traição e a inveja. "Mas os ódios já existem, o que ocorre é que eles são abafados. Se meu projeto não passou, o dia em que eu virar poderoso: Ah, você vai ver o que vai acontecer com você. Quer dizer, os ódios são incubados e potencializados" (Romano, 1999, p.25). "Só que o C... se deixou envolver por uma AIDS que existe no serviço público, que se chama vaidade" (Garisto, 2000, p.26).

Na política, se você tem um propósito ou uma idéia, muitas vezes é melhor deixar que o outro pense que o propósito ou a idéia é dele, porque senão o outro vai ficar contra você. Na ciência, o outro que se dane, o ego do cientista tem que ser maior que o do político. O político não pode ser vaidoso, o intelectual pode e até deve. O político tem que ser humilde. É difícil isso para um intelectual como eu. Você aprende a duras penas, porque a vontade é dizer 'eu sou o melhor e não pode'. (Cardoso apud Carta, 2001, p.4)

O exercício do poder $e$ a Instituição

A base da inveja é a busca do poder: a mais valia, valer mais. Em qualquer estágio, qualquer lugar que esteja o ser humano, muda só a quantidade de inveja. Só sua cultura é diferente....concorda com a afirmação de que a inveja é maior entre pares, entre iguais. (Ventura, 1998, p.137)

Para Enriquez (1991), a instituição é um lugar onde se encontram diferentes tipos de auxiliares que ocupam status e funções teoricamente estabilizadas $e$ entre os quais se estabelecem relações de poder. Se nas organizações industriais, os membros estão conscientes tanto da necessidade de cooperação quanto das relações de forças instituídas que podem desembocar em momentos de ruptura, o mesmo não se dá nas instituições, usando como exemplo uma instituição terapêutica, que vivem sob a égide de uma ideologia igualitária, em que a cooperação entre iguais é apresentada como uma necessidade, mas imediatamente desmentida, em que a "ação dos outros apenas constitui um entrave e onde o ciúme e a rivalidade vão se manifestar no que diz respeito às técnicas" (p.69) e à "posse" do saber. Essas relações de poder - que jamais podem se exprimir tais como são, tornam difícil, senão impossível, o tratamento de casos evocados.

A vida intelectual é uma hierarquia como qualquer outra. Tem uma elite, um contingente médio que carrega o piano e um baixo clero, insatisfeito, que ganha mal, procurando oportunidades de respiro na 


\begin{abstract}
política, no jornalismo. Às vezes, não procura a política por boas razões. Não é o caso do Fernando Henrique. Mas muitos intelectuais entre aspas se bandeiam para a atividade política porque na verdade, estão esterilizados, estão insatisfeitos, estão ressentidos, estão insatisfeitos. Fizeram a vida intelectual porque não acharam coisa melhor para fazer. (Micelli, 2001, p. 23)

Existem muitos professores que vêem a universidade como uma forma de currículo, uma forma de trampolim do próprio meio político, né? Ele vê a universidade em si como um meio de subida (fala de funcionário, Souto, 1993, p.303)
\end{abstract}

Há maior "flexibilidade", maior aceitação de injustiças no meio do trabalho. Existe também o individualismo (Gerreiro \& Anderson, 1998), a não mistura com coisas do outro. O pré-julgamento sem procurar se inteirar ou compreender os fatos verdadeiros: "Se existe alguma coisa, é porque algo de errado fez" (p.33). Além do mais, existe a questão da subjetividade, quando podemos nos resvalar com sentimentos como a inveja, a vaidade, o medo e o desejo do poder. As motivações ocultas são de diversas ordens e sua complexidade não é facilmente abordável.

\title{
Instituição, a sagrada família
}

Para Kaes (1991), que aborda o tema das instituições num olhar psicanalítico, a instituição é, em primeiro lugar, uma formação da sociedade e da cultura, com sua própria lógica, com um conjunto de formas e estruturas instituídas pela lei e o costume; cada instituição é dotada de uma finalidade que a identifica $e$ a distingue, $e$ as diferentes funções podem ser classificadas em três grandes grupos: funções jurídico-religiosas, defensivas $e$ de ataque e as funções produtoras - reprodutoras. Em segundo, ela realiza funções psíquicas múltiplas para os indivíduos em sua estrutura, em sua dinâmica e em sua economia pessoal. Ela mobiliza investimentos e representações que contribuem para a regulação endopsíquica e que asseguram as bases da identificação do sujeito com o conjunto social. Para realizar suas funções específicas, não psíquicas, a instituição deve mobilizar formações e processos psíquicos em que principalmente aqueles que ela contribui para formar ou que ela recebe em depósito, serão particularmente solicitados; admite-se sobretudo que formações psíquicas originais são produzidas e mantidas pela vida institucional visando seus próprios fins: isso significa que se trata de formações que correspondem à dupla necessidade da instituição e dos sujeitos que delas são parte integrante e beneficiária. Essas formações constituem a possibilidade de espaços psíquicos comuns e compartilhados, supondo a construção, a utilização ou a organização de um aparelho psíquico de ligação, de transmissão e de transformação de agrupamento. Considera, ainda, o agrupamento, citando Anzieu, como um lugar para realizar os desejos e para se defender contra sua realização; de um lado, a celebração pelo grupo, que se institui e se desinstitui continuamente, da função criadora do imaginário social $e$ da realização dos desejos "individuais". Por outro lado, denúncia da instituição instituída e alienante e que pereniza a rigidificação do movimento social, a permanência 
dos poderes coercitivos e a hierarquia dos valores oponíveis à satisfação do desejo.

O agrupamento, como formação psíquica intermediária, é o que na instituição une os membros da instituição entre si, numa realização do tipo onírico e pela comunidade dos sintomas, das fantasias e das identificações, de tal forma que possam investir aí os desejos recalcados e encontrar os meios deformados, desviados, travestidos, de os realizar ou de se defender deles. Por aí eles se ligam à instituição, ao seu ideal, ao seu projeto, ao seu espaço.

Bourdieu (apud Hochman, 1994) considera que uma das características mais importantes do mundo intelectual é o caráter fechado de uma comunidade que compartilha um "espírito comum"; a autarquização - devida à autonomização deste universo mais do que qualquer outro campo social - produz um grupo que assume a feição de uma "seita ou igrejinha" É devido a esse traço que se pode perceber no comportamento desses intelectuais uma tendência a autoreprodução. Por um lado isso significa proclamar o divórcio dos intelectuais em relação às demandas sociais $e$, por outro, dizer que sua prática e identidade social se definem por intermédio de sua inscrição acadêmica.

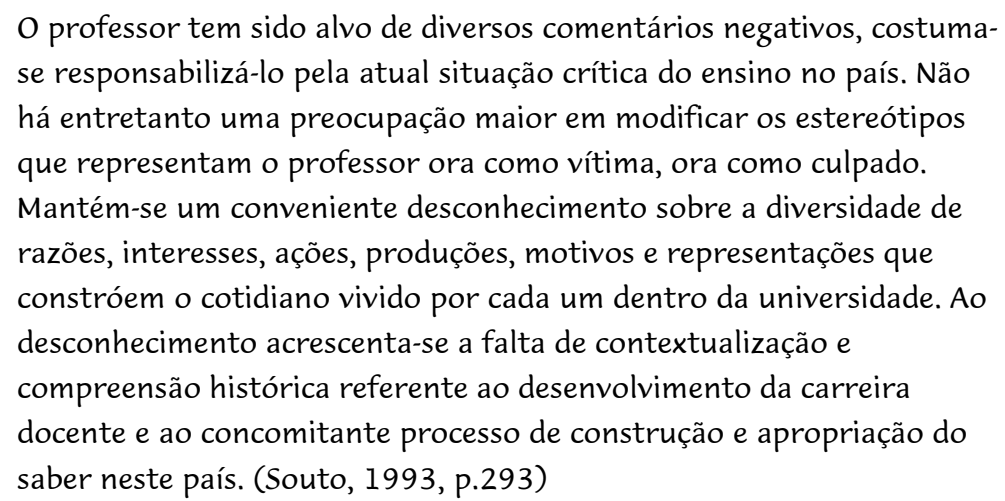

A universidade foi apresentada como uma instituição esquecida pelo governo do Estado, não recebendo a devida importância. "A universidade está assim: completamente jogada às traças"(fala de um professor) "também tem a universidade como um bico, então eles vêm aqui, dão a aula deles e vão embora e acabou-se" (fala de um professor, Souto, p.303). Em seu estudo, Souto (1993) conclui que alunos e funcionários atribuem ao professor funções e responsabilidades que são mais pertinentes ao âmbito socioinstitucional do que ao individual.

Para Nogueira (2001), nos últimos trinta anos os intelectuais perderam progressivamente a possibilidade de continuar desempenhando o papel de serem produtores de sentido para a sociedade: ficaram com mais dificuldade de dialogar com as pessoas e de serem por elas compreendidos, mergulharam nas instituições e se deixaram burocratizar; passaram a ter um público sem precisar ser um intelectual público - seus vínculos são estabelecidos com a rede institucional em que atuam. Correndo pela margem, dentro das instituições, um imaginário construído por picuínhas departamentais, retóricas inflamadas, lutas por posições administrativas e glórias fugazes... existe a burocracia "que dificulta a expressão de descontentamento" (Romano, 1999, p.29). 


\begin{abstract}
Nesse sentido, convém que vários institutos concorram ferozmente entre si, pelo sucesso e pelas verbas, incrementando o desempenho coletivo. O que força as equipes a rivalizar ente si, os professores a competir uns com os outros, e naturalmente os alunos a disputarem as bolsas, migalhas e vagas nas salas superlotadas. Convém ao conjunto do sistema que todos sejam mal aquinhoados, porque só assim sentirão o devido acicate para multiplicar as verbas escassas (Sevcenko, 2000, p.7).
\end{abstract}

Para Bourdieu (apud Hochman, 1994), o campo científico é um campo de lutas, estruturalmente determinado pelas batalhas passadas, no qual agentes/ cientistas buscam o monopólio da autoridade/competência científica. Os conflitos que ocorrem no e pelo domínio desse campo são entre agentes que têm lugares socialmente prefixados no mesmo, assim como qualquer agente na sociedade, e são fundamentalmente interessados, isto é, desejam maximizar, e se puderem, monopolizar, a competência/autoridade científica - reconhecida pelos pares. O campo científico instaura-se com um conflito pelo crédito científico. Portanto, o campo científico como locus de análise se distancia muito da comunidade de especialistas que cooperam para o avanço do conhecimento. $\mathrm{O}$ crédito científico é um capital simbólico, não monetário - a autoridadel competência científica - uma espécie particular de capital "que pode ser acumulada, transmitida e até reconvertida, sob certas condições em outro tipo de capital' (p.209) em um mercado específico, o da produção de conhecimento científico. Assim, Bourdieu não faz apenas uma analogia do campo científico com o mercado capitalista, mas indo além, propõe que este é um mercado particular dentro da ordem econômica capitalista! (Hochman, 1994).

\title{
Por que sofremos?
}

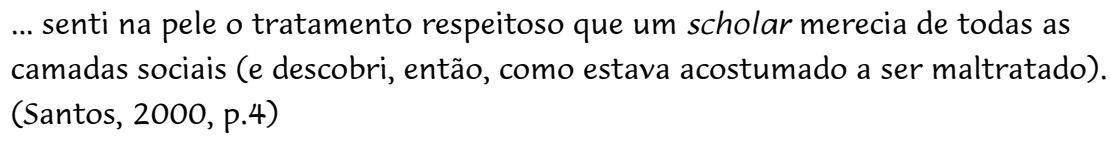

A traição com todas as suas motivações, leva ao sofrimento mental dos traídos e talvez dos que traem. Considerando a carga psíquica, no aparecimento das manifestações clínicas, Dejours (1994) aponta para duas possibilidades, em função da estrutura mental: a descompensação psiconeurótica e a descompensação somática. Caso se trate de uma estrutura psicótica, a sobrecarga poderá produzir um quadro de delírio; se a estrutura for neurótica, uma depressão ou ainda, uma doença somática, se ocorrer uma desorganização mental.

Kaes (1991) considera que muitas vezes o estudo dos processos e estruturas psíquicas das instituições só é acessível a partir do sofrimento que aí se experimenta, o qual apresenta alguns aspectos que dizem respeito a uma verdadeira patologia da vida institucional. Considera três fontes de sofrimento que podem ser distinguidas pela análise, que aparecem intrincadas na queixa ou na designação da causa: uma é inerente ao próprio fato institucional, outra a uma determinada instituição específica, a sua estrutura social e a sua estrutura 
inconsciente própria e a terceira, à configuração psíquica do sujeito singular.

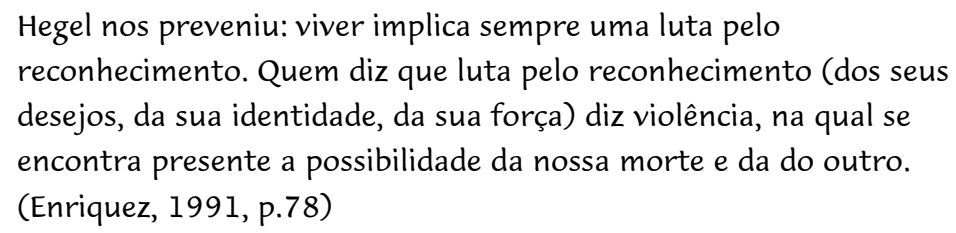

Nós sofremos pela nossa relação com a instituição, sofremos nessa relação; é por projeção que sofrem os sujeitos da instituição, é a instituição em nós, o que em nós é a instituição, que se encontra sofrendo. Sofremos devido a contratos, pactos, comunidade e acordos inconscientes ou não, que nos unem em uma relação assimétrica, desigual, na qual a violência necessariamente é exercida, na qual se experimenta necessariamente a distância entre a exigência $e$ os benefícios esperados. Sofremos com o excesso da instituição e também com sua falha, com o fracasso para garantir os termos dos contratos e dos pactos, para tornar possível a realização da tarefa primária que motiva o lugar dos sujeitos em seu seio. E sofremos também por não compreender a causa, o objeto, o sentido e a própria razão do sofrimento que experimentamos (Enriquez, 1991).

Ainda segundo o mesmo autor, a violência parece ser substancial para a vida institucional, na medida em que procede da legalidade que exige que os homens renunciem à satisfação de suas pulsões e na medida em que, fazendo isso, é capaz de reacender os combates entre os iguais e favorecer o desejo de transgressão das interdições; mas a violência institucional não se reduz à violência legal (Enriquez, 1991).

As características pessoais são mobilizadas no mundo do trabalho e acabam interferindo na carreira profissional dos afetados, mudando seu curso; a instituição sai prejudicada em última instância, pois agressores e agredidos dedicam-se a atividades que em nada contribuem à construção do conhecimento e da pesquisa. A instituição tende a perder essas competências, seja pela saída do profissional da instituição ou pela impossibilidade de utilizar os conhecimentos e experiências adquiridos ao longo de sua carreira. Parecenos que as pessoas que traem direta ou indiretamente, apresentam escassas reflexões íntimas de caráter ético (Enriquez, 1991).

A traição no trabalho é sempre um processo coletivo; raramente estes fatos ocorreriam se levados por uma só pessoa isoladamente. Para reforçar sua natureza coletiva aqui fazemos nossas as palavras de Dejours (1999, p.132):

O que mudou foi a gestão da empresa. Hoje, a base da política pessoal repousa na ameaça ininterrupta aos assalariados, condições e locais de trabalho (...) Antes, se um chefe perseguia alguém, se um empregador fraudava a folha de pagamento de seus operários, se alguém violava os direitos do trabalho, todo mundo entendia isso como uma coisa errada (...) Hoje essas técnicas não são apenas utilizadas, como se tornaram legítimas (...) É necessário que haja alguém que maltrate, humilhe e intimide pelo medo. E também gente que veja tudo e não diga nada. $\mathbf{O}$ sistema não caminha sozinho. A gente vê as pessoas serem 
humilhadas e prejudicadas a nossa volta, mas não protesta. A gente aceita as injustiças. Tal consentimento coloca um enorme problema para a maioria de nós, porque temos senso moral. É isso que cria essa forma específica de sofrimento, que é o sofrimento ético: um conflito moral e emocional consigo mesmo. E atrás de tudo isso se esconde uma profunda crise de identidade, pois se sou testemunha de que meu chefe prejudica um colega que não merece isso, mas apesar disso me calo, sei que no fundo sou covarde. E se sou covarde, perco a confiança em mim e nos outros, porque eles se conduzem como eu. Essa desestabilização pode levar à depressão ou a formas mais trágicas como o suicídio, principalmente em locais de trabalho.

Poderíamos supor que essas traições possam ser formas de defesa coletiva, constituindo exploração do sofrimento pela organização do trabalho, onde

as estratégias coletivas de defesa também funcionam como sistema de seleção psicológica dos trabalhadores, guardando no seio do coletivo os trabalhadores que trazem contribuição à defesa, eliminando sem dó aqueles que se mostram reticentes, chegando a perseguí-los, e às vezes a considerá-los como bodes expiatórios do sofrimento. (Dejours, 1994, p.132)

\section{Referências bibliográficas:}

ANDERSON, R. Envy and jealousy. J. College Studant Psychotherapy, v.1, n.4, p.49-81, 1987.

BRESSER PEREIRA, L.C. A sagrada missão pública. Folha de São Paulo. São Paulo, 04 jun. 2000. Mais! p.10-1.

CARTA, M. Entrevista FHC. Carta Capital, p.4, 20 jun. 2001.

CHAUÍ, M. Todo mundo tem de viver uma grande paixão e uma possibilidade de revolução. (Entrevista) Caros Amigos, n.29, p.22-8, ago. 1999.

DEJOURS, C. A violência invisível (Entrevista) Caros Amigos, n.26, p.16-7, maio 1999.

DEJOURS, C., ABDUCHELI, E., JAYET, C. Psicodinâmica do trabalho. São Paulo: Atlas, 1994.

ENRIQUEZ, E. O trabalho da morte nas instituições. In:___ Trad.: J. Pereira Neto. A instituição e as instituições: estudos psicanalíticos. São Paulo: Casa do Psicólogo, 1991. p.53-79.

FELDMAN, E., DE PAOLA, H. Uma investigação sobre o conceito psicanalítico de inveja. Rev. Bras. Psicanálise, v.32, n.2, p.223-49, 1998.

FREIRE COSTA, J. A ansiedade da opulência. Folha de São Paulo. São Paulo, 19 mar. 2000. Mais!, p.19.

GARISTO, F.C. Polícia de verdade. (Entrevista) Caros Amigos, n.36, p.24-31, mar. 2000.

GAULEJAC, V. Envie intime, envie sociale. L'envie, un sentiment social. Rev. Française Psychanalyse, n.61, p.111-22, 1997.

GUERREIRO,L.K., ANDERSEN, P. A. The dark side of jealously and envy: desire, delusion, desperation and destructive communication. In: SPITZBERG, B.H. (Eds.) The dark side of close relationship. New Jersey: Lawrence Erlbaum Associates, 1998. p.33-70

HOCHMAN, G. A Ciência entre a Comunidade e o Mercado: leituras de Kuhn, Bourdieu, Latour e Knorr-Cetina. In: CARRERO, V. Filosofia, História e Sociologia das Ciências. Rio de Janeiro: FIOCRUZ, 1994. p.199-231.

HORNER, A.J. The wish for power and the fear of having it. New Jersey: Jason Aronson, 1989.

KAES, R. (Org.). A instituição e as instituições: estudos psicanalíticos. São Paulo: Casa do Psicólogo, 1991. LEWIS, M. (Org.) Lying and deception in everyday life. New York: Guilford Press, 1993. 
IGUTI, A. M.

LIMA, I. C. Marginais aqui e lá. Folha de São Paulo. São Paulo, 04 jun, 2000. Mais! p.12-3.

MASSINI, N. O caçador de desaparecidos. (Entrevista) Caros Amigos, n. 24, p.22-9, mar. 1999.

MICELLI, S. Entrevista a Carta Capital, p.21-3, 20 jun. 2001.

MILTON SANTOS. O território revela que o Brasil é um país não governado. (Entrevista) Caros Amigos, n.17, p.12-7, ago. 1998, republicado dez. 2000.

NOGUEIRA, M. A. O saber oculto. Carta Capital, p.27, 20 jun. 2001.

REPUBLICA. Caros Amigos, v.4, n.40, p.28-9, jul. 2000.

ROMANO, R. O ministro Paulo Renato mente. (Entrevista) Caros Amigos, n.23, p.22-9, fev. 1999.

ROUSSILLON, R. Espaços e práticas institucionais: o quarto de despejo e o insterstício. In: Trad. J. Pereira Neto. A instituição e as instituições: estudos psicanalíticos. São Paulo: Casa do Psicólogo, 1991. p.133-55.

SADER, E. O estatal, o público e o privado na educação. Caros Amigos, v.4, n.40, p.27, 2000.

SANDELL, R. Envy and admiration. Int. J. Psychoanal., v.74, n.6, p.1213-21, 1993.

SANTOS, L.G. O fim da Universidade. Folha de São Paulo. São Paulo, 4 jun. 2000. Mais! p.4-5.

SEVCENKO, N. O professor como corretor. Folha de São Paulo. São Paulo, 4 jun. 2000. Mais! p.6-7.

SHENGOLD, L. Envy and malignant envy. Psychoanalytic Quartely, v.63, p.615-41, 1994.

SMITH, R.H., PARROT, W., GERROD, W., OZER, D, MONIZ, A. Subjetive injustice and inferiority as predictors of hostile and depressive feelings in envy. Personal. Soc. Psychol. Bull., v.20, n.6, p.705-11, 1994.

SOUTO, S. O. O jogo de papéis e representações sociais na universidade: o estudo de um caso particular. In: SPINK, M.J. (Org.) O conhecimento cotidiano. São Paulo: Brasiliense, 1993. p.292-311.

TEIGEN, K.H. Luck, envy and gratitude: it could have been different. Scand. J. Psychol., v.38, n.4, p.313-23, 1997.

VENTURA, Z. Inveja, mal secreto. Rio de Janeiro: Objetiva, 1998.

WIENER, J. O caso americano. Folha de São Paulo. São Paulo, 4 jun. 2000. Mais! p.14-5.

IGUTI, A. M. La traición en las relaciones de trabajo de la Universidad, Interface - Comunic, Saúde, Educ, v.6, n.11, p.89-104, 2002.

Se trata de un pequeño ensayo, en el cual planteamos algunos puntos para reflexión sobre la universidad y la traición en las relaciones de trabajo que, a nuestro parecer, se han intensificado en los últimos años. Tomando como referencia las declaraciones de académicos $e$ investigadores y la literatura disponible, se intentó contextualizar el mundo del trabajo en la universidad, con sus actuales dinámicas que propician este tipo de actitud. Se plantearon algunas posibilidades del porqué de su ocurrencia, entre ellas, las cuestiones del poder y de la envidia. Se considera que la traición puede ser un indicio de la degradación de las relaciones humanas, en una perspectiva individualista, contra la solidariedad y lo colectivo del trabajo.

PALABRAS CLAVE: Universidad; relaciones interprofesionales; trabajo.

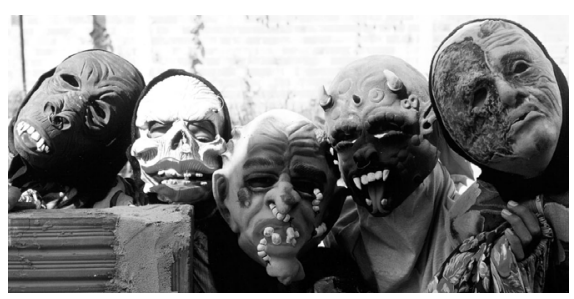

Recebido para publicação em: 30/01/02 Aprovado para publicação em: 12/06/02

104 Interface - Comunic, Saúde, Educ, v6, n11, p.89-104, ago 2002 